\title{
Associations between Relationship Quality and Mental Health during COVID-19 in the United Kingdom
}

\author{
Christoph Pieh ${ }^{1, *(\mathbb{D}}$, Thomas Probst ${ }^{1}\left(\mathbb{D}\right.$, Sanja Budimir ${ }^{1,2}$ and Elke Humer $^{1}(\mathbb{D}$ \\ 1 Department for Psychotherapy and Biopsychosocial Health, Danube University Krems, \\ 3500 Krems an der Donau, Austria; thomas.probst@donau-uni.ac.at (T.P.); \\ sanja.budimir@donau-uni.ac.at (S.B.); elke.humer@donau-uni.ac.at (E.H.) \\ 2 Department of Work, Organization and Society, Ghent University, 9000 Gent, Belgium \\ * Correspondence: christoph.pieh@donau-uni.ac.at
}

Citation: Pieh, C.; Probst, T.;

Budimir, S.; Humer, E. Associations between Relationship Quality and Mental Health during COVID-19 in the United Kingdom. Int. J. Environ Res. Public Health 2021, 18, 2869.

https://doi.org/10.3390/ ijerph18062869

Academic Editor: Paul B. Tchounwou

Received: 25 February 2021

Accepted: 9 March 2021

Published: 11 March 2021

Publisher's Note: MDPI stays neutral with regard to jurisdictional claims in published maps and institutional affiliations.

Copyright: (c) 2021 by the authors. Licensee MDPI, Basel, Switzerland. This article is an open access article distributed under the terms and conditions of the Creative Commons Attribution (CC BY) license (https:// creativecommons.org/licenses/by/ $4.0 /)$.

\begin{abstract}
This study investigated the association of relationship quality with several well-being measures during the COVID-19 lockdown in the United Kingdom. An online survey was conducted on a study sample $(n=682)$ measuring relationship quality with the Quality of Marriage Index, and well-being measures including quality of life (WHO-QoL BREF), well-being (WHO-5), perceived stress (PSS-10), depressive (PHQ-9), and anxiety (GAD-7) symptoms. Good relationship quality goes along with higher scores in well-being (WHO-5), quality of life (WHO-QoL BREF), psychological domain, physical health, social relationships, environment, and reduced scores in stress (PSS-10), depressive (PHQ-9) and anxiety (GAD-7) symptoms compared with poor relationship quality $(p<0.001)$. Moreover, $21 \%$ of participants living in relationships with poor quality stated that they drink significantly more alcohol since the initial COVID-19 restrictions, compared to $10 \%$ of participants with good quality $(p=0.002)$. Living in a good relationship seems to be an advantage, whereas those with poor relationship quality are particularly more burdened and drink significantly more alcohol during the COVID-19 lockdown.
\end{abstract}

Keywords: relationship quality; COVID-19; mental health; life quality; well-being

\section{Introduction}

The lockdown due to the COVID-19 pandemic limited and focused social interactions to interactions within a household, resulting in increased frequency of contact between partners. We aimed to evaluate the effect of relationship quality on various mental health and well-being indicators during the COVID-19 lockdown.

Relationship status and relationship quality have been reliably associated with health benefits and mental well-being [1-3]. For example, marital quality significantly predicts well-being measures, such as satisfaction with life, stress, or depression, but also physiological parameters, such as blood pressure [4]. Vice versa, loneliness can lead to various psychiatric disorders, such as depression or sleep problems, as well as physical disorders, such as diabetes or cardiovascular diseases [5].

The current coronavirus disease 2019 (COVID-19) pandemic and the governmental restrictions constitute an extraordinary situation for relationships and mental well-being [6]. To prevent the uncontrolled spreading of the virus, most governments imposed a national lockdown. In the UK, the lockdown became obligatory on 24 March 2020. During the lockdown, the population was required to adhere to quarantine with only a few exceptions justifying leaving the house (e.g., shopping for food and other necessities; exercising alone or with someone from the same household; for medical reasons including providing care to others; and traveling to and from work).

As known as a result of previous disasters, such challenging times can have an impact on relationships, marriage, and divorce rates [7]. However, as the COVID-19 lockdown is unique and difficult to compare with, the impact of relationship quality on well-being is 
unclear. However, it is likely that during lockdown measures the relationship quality has a particular influence on well-being. Therefore, the current study evaluates the impact of relationship quality on well-being indicators during the COVID-19 lockdown in the UK.

\section{Materials and Methods}

A representative study sample according to age, gender, education, and region for the UK was recruited through the Qualtrics ${ }^{\circledR}$ population survey platform by quota sampling on 1006 participants. From the total sample, those living in a relationship were included in this study. Relationship quality was assessed during the lockdown (i.e., 4 weeks after its start, 21 April-31 April) with the Quality of Marriage Index (QMI) [8] using the recommended cut-off score of $\geq 34$ to distinguish between good and poor relationship quality [9]. Furthermore, well-being (WHO Well-being Index: WHO-5) [10], quality of life (WHO-QoL BREF) [11], stress (Perceived Stress Scale: PSS-10) [12], depressive symptoms (Patient Health Questionnaire: PHQ-9) [13], and anxiety (Generalized Anxiety Disorder 7 scale: GAD-7) [14] were measured. Additionally, the drinking behavior of alcoholic beverages was assessed using the following question: "Has your drinking behavior of alcoholic beverages such as beer, wine, or spirits changed since the initial restrictions?". Participants had to choose between four answer options: "I don't drink alcohol, I drink as much alcohol as I did before", "I drink significantly less alcohol than before", "I drink significantly more alcohol than before". All data were analyzed using SPSS ${ }^{\circledR}$ version 26 (IBM Corp, Armonk, NY, USA). Descriptive statistic was used to describe the demographic characteristics and scales mean values. Mental health scale data were analyzed for normality using the Shapiro-Wilk test, which confirmed non-normal distributions. As for large sample sizes, non-parametric tests are not recommended [15], differences between good and poor relationships concerning all metric outcome variables were analyzed using $\mathrm{t}$-tests, whereas chi-squared tests were applied for nominal data. The two-sided significance level was set at $<0.05$. Cohen's d was calculated for the effect size.

\section{Results}

Within the study sample $(N=1006), n=682$ are currently living in a relationship comprising $52.8 \%$ females and $47.2 \%$ males. Further sample characteristics are summarized in Table 1.

Table 1. Study sample characteristics $(n=682)$.

\begin{tabular}{lccc}
\hline & Variable & $\boldsymbol{N}$ & $\%$ \\
\hline Gender & Women & & \\
& Men & 360 & 52.8 \\
Age & $18-24$ & 322 & 47.2 \\
& $25-34$ & 47 & 6.9 \\
& $35-44$ & 147 & 21.6 \\
& $45-54$ & 135 & 19.8 \\
& $55-64$ & 131 & 19.2 \\
& $65+$ & 120 & 17.6 \\
Marital Status & 102 & 15.0 \\
& Single & & \\
& Separated & 68 & 10.0 \\
& Married & 2 & 0.3 \\
& Divorced & 405 & 59.4 \\
Region & Living as married & 18 & 2.6 \\
& Widowed & 187 & 27.4 \\
& North East & 2 & 0.3 \\
& North West & 33 & 4.8 \\
& Yorkshire and The Humber & 84 & 12.3 \\
& & 63 & 9.2 \\
\hline
\end{tabular}


Table 1. Cont.

\begin{tabular}{|c|c|c|}
\hline Variable & $N$ & $\%$ \\
\hline East Midlands & 56 & 8.2 \\
\hline West Midlands & 58 & 8.5 \\
\hline East of England & 61 & 8.9 \\
\hline London & 66 & 9.7 \\
\hline South East & 92 & 13.5 \\
\hline South West & 58 & 8.5 \\
\hline Wales & 36 & 5.3 \\
\hline Scotland & 58 & 8.5 \\
\hline Northern Ireland & 17 & 2.5 \\
\hline \multicolumn{3}{|l|}{ Education } \\
\hline None at all & 9 & 1.3 \\
\hline Elementary school & 23 & 3.4 \\
\hline Trade/technical/vocational training & 107 & 15.7 \\
\hline High school or equivalent & 267 & 39.1 \\
\hline College & 81 & 11.9 \\
\hline Bachelor's degree & 109 & 16.0 \\
\hline Master's degree & 66 & 9.7 \\
\hline Doctoral degree & 12 & 1.8 \\
\hline Professional degree (MD, JD, etc.) & 8 & 1.2 \\
\hline \multicolumn{3}{|l|}{ Net household income } \\
\hline less than GBP 900,- & 60 & 8.8 \\
\hline from GBP 900,- equal to GBP 1800,- & 209 & 30.6 \\
\hline more than GBP 1800 ,- equal to GBP 2700,- & 202 & 29.6 \\
\hline more than GBP 2700 ,- equal to GBP $3600,-$ & 115 & 16.9 \\
\hline more than GBP 3600,- & 96 & 14.1 \\
\hline \multicolumn{3}{|l|}{ Job situation } \\
\hline No paid work (also before the lockdown) & 140 & 20.5 \\
\hline No paid work since the lockdown & 161 & 23.6 \\
\hline Home office & 132 & 19.4 \\
\hline Paid work at the workplace (no home office) & 100 & 14.7 \\
\hline Paid work, but reduced hours since lockdown & 48 & 7.0 \\
\hline Retired & 101 & 14.8 \\
\hline
\end{tabular}

According to the QMI, $n=500$ are living in a relationship with good and $n=182$ are living in a relationship with poor quality. Chi-squared tests revealed no differences concerning age, gender, educational level, job situation, and net income between participants living in good or poor relationships (all $p$ values $\geq 0.09$ ). T-tests revealed that individuals with good relationships had significantly better outcomes in all measured scales than those with a poor relationship (all $p$ values $<0.001$; effect sizes ranged from $d=0.37$ to $d=1.21$; Table 2).

Table 2. Measures of well-being and mental health during the COVID-19 lockdown in individuals with good $(n=500)$ or poor $(n=182)$ relationship.

\begin{tabular}{ccccc}
\hline Variable & Unit & Good Relationship & Poor Relationship & Statistic \\
\hline WHO-5 & M & 14.46 & 10.79 & $t(680)=7.60 ;$ \\
WHO-QoL BREF & SD & 5.61 & 5.47 & $p<0.001 ; d=-0.66$ \\
Psychological & & & & $t(680)=9.97 ;$ \\
& M & 65.66 & 49.47 & $p<0.001 ; d=-0.86$ \\
Physical health & SD & 18.74 & 18.77 & $t(680)=4.33 ;$ \\
Social relationships & M & 69.11 & 61.58 & $p<0.001 ; d=-0.37$ \\
& SD & 20.52 & 18.98 & $t(284.9)=13.06 ;$ \\
Environment & M & 72.40 & 48.63 & $p<0.001 ; d=-1.21$ \\
& SD & 18.81 & 21.79 & $t(680)=8.97 ;$ \\
PSS-10 & M & 69.53 & 56.28 & $p<0.001 ; d=-0.78$ \\
& SD & 17.17 & 16.71 & $t(365.4)=-8.10 ;$ \\
\hline
\end{tabular}


Table 2. Cont.

\begin{tabular}{ccccc}
\hline Variable & Unit & Good Relationship & Poor Relationship & Statistic \\
\hline & SD & 7.69 & 6.71 & $p<0.001 ; d=0.66$ \\
PHQ-9 & M & 7.26 & 12.15 & $t(680)=-7.88 ;$ \\
& SD & 7.04 & 7.55 & $p<0.001 ; d=0.68$ \\
GAD-7 & M & 6.81 & 10.70 & $t(680)=-7.20 ;$ \\
& SD & 6.13 & 6.50 & $p<0.001 ; d=0.62$ \\
\hline
\end{tabular}

$p$ : $p$-values (two-tailed); M: mean score; SD: standard deviation, $t: t$-test; $d$ : Cohen's d, an effect size, GAD-7: Generalized Anxiety Disorder 7 scale; PHQ-9: Patient Health Questionnaire 9 scale; PSS-10: Perceived Stress Scale 10; WHO-5: Well-being questionnaire of the World Health Organization (WHO); WHO-QoL BREF: Quality of Life questionnaire of the World Health Organization (WHO).

Additionally, it was found that $21 \%$ of participants who are living in a relationship with poor quality stated that they now drink significantly more alcohol than before the lockdown measures, compared to $10 \%$ of participants with good relationship quality $\left(\chi^{2}(3)=14.72 ; p=0.002\right.$; Table 3).

Table 3. Drinking behavior of alcoholic beverages since the initial COVID-19 restrictions in individuals with good $(n=500)$ or poor $(n=182)$ relationship.

\begin{tabular}{ccccc}
\hline Alcohol Consumption & Unit & $\begin{array}{c}\text { Good } \\
\text { Relationship }\end{array}$ & $\begin{array}{c}\text { Poor } \\
\text { Relationship }\end{array}$ & Statistic \\
\hline I don't drink alcohol & $\mathrm{F}$ & 156 & 50 & $\chi^{2}(3)=14.72 ;$ \\
& $\%$ & 31.2 & 27.5 & \\
I drink as much alcohol & $\mathrm{F}$ & 235 & 75 & \\
as I did before & $\%$ & 47.0 & 41.2 & \\
I drink significantly less & $\mathrm{F}$ & 60 & 19 & \\
alcohol than before & $\%$ & 12.0 & 10.4 & \\
I drink significantly more & $\mathrm{F}$ & 49 & 38 & \\
alcohol than before & $\%$ & 9.8 & 20.9 & \\
\hline
\end{tabular}

p: $p$-values (two-tailed); F: frequencies; \%: percentages; $\chi^{2}$ : Chi-squared-test.

\section{Discussion}

The current study explored the effect of the relationship quality on well-being indicators during the COVID-19 lockdown in the UK. Results suggest that good relationship quality is positively associated with well-being and mental health during the challenging situation around the COVID-19 pandemic. Individuals living in a relationship with a poor quality experience more of the mental burden during the COVID-19 lockdown and drink more alcohol during the COVID-19 lockdown.

The observed association of good relationship quality and mental well-being corresponds to previous research [5]. Previous studies revealed associations between relationship quality and mental well-being, with better mental health in married individuals compared to never-married ones [2]. It has also been reported that married women and men consume less alcohol and have fewer drinking problems compared to singles or divorced individuals [16]. However, it seems that quality of the relationship, rather than being married per se, is crucial for well-being, as unhappily married individuals have been shown to have worse mental health than singles [1,4]. Our findings indicate that the beneficial association of sharing life with a partner and mental well-being is present only for those living in a relationship with good quality, whereas those living in a relationship with a poor quality showed deteriorated mental health, well-being, and life quality.

A main limitation of the study is that no causal conclusions are possible about changes in the effect of relationship quality on well-being and mental health due to the COVID-19 restrictions. A longitudinal study with a further survey conducted before the COVID-19 lockdown would have been more appropriate to draw causal conclusions whether relationship quality affected well-being or whether well-being affected relationship quality or both. A further limitation is that only self-rating scales and no clinician-based assessments 
were applied. Another limitation is the unequal sample size of participants among the relationship quality groups $(n=182$ in the group with poor relationships vs. $n=500$ in the group with good relationships), which impedes the robustness of statistical tests.

\section{Conclusions}

During a COVID-19 lockdown, relationship quality seems to be positively associated with well-being and mental health. Individuals with poor relationship quality are not only particularly more burdened compared with those with good relationship quality, but also drink significantly more alcohol during the COVID-19 lockdown.

Author Contributions: Conceptualization: C.P., S.B., and T.P.; methodology: C.P., S.B., and T.P.; formal analysis: E.H.; investigation: C.P. and S.B.; data curation: S.B.; writing-original draft preparation: E.H. and C.P.; writing-review and editing: S.B. and T.P. All authors have read and agreed to the published version of the manuscript.

Funding: Open Access Funding by the University of Continuing Education Krems.

Institutional Review Board Statement: The study was conducted according to the guidelines of the Declaration of Helsinki, and approved by the Ethics Committee of Danube University Krems, Austria (Ethical number: EK GZ 26/2018-2021).

Informed Consent Statement: Informed consent was obtained from all subjects involved in the study. All participants gave electronic informed consent for participation and completing the questionnaires. Data were collected anonymously without IP addresses or GPS tracking and this procedure was approved by the data protection officer of the Danube-University Krems.

Data Availability Statement: The raw data supporting the conclusion of this article will be made available by the authors upon reasonable request.

Conflicts of Interest: The authors declare no conflict of interest. The funders had no role in the design of the study; in the collection, analyses, or interpretation of data; in the writing of the manuscript, or in the decision to publish the results.

\section{References}

1. Chapman, B.; Guven, C. Revisiting the Relationship Between Marriage and Wellbeing: Does Marriage Quality Matter? J. Happiness Stud. 2016, 17, 533-551. [CrossRef]

2. Hsu, T.-L.; Barrett, A.E. The Association between Marital Status and Psychological Well-Being: Variation across Negative and Positive Dimensions. J. Fam. Issues 2020, 41, 2179-2202. [CrossRef]

3. Leach, L.S.; Butterworth, P.; Olesen, S.C.; Mackinnon, A. Relationship Quality and Levels of Depression and Anxiety in a Large Population-Based Survey. Soc. Psychiatry Psychiatr Epidemiol. 2013, 48, 417-425. [CrossRef]

4. Holt-Lunstad, J.; Birmingham, W.; Jones, B.Q. Is There Something Unique about Marriage? The Relative Impact of Marital Status, Relationship Quality, and Network Social Support on Ambulatory Blood Pressure and Mental Health. Ann. Behav. Med. 2008, 35, 239-244. [CrossRef] [PubMed]

5. Mushtaq, R. Relationship Between Loneliness, Psychiatric Disorders and Physical Health? A Review on the Psychological Aspects of Loneliness. JCDR 2014, 8, WE01-WE04. [CrossRef] [PubMed]

6. Zhou, X.; Snoswell, C.L.; Harding, L.E.; Bambling, M.; Edirippulige, S.; Bai, X.; Smith, A.C. The Role of Telehealth in Reducing the Mental Health Burden from COVID-19. Telemed. e-Health 2020, 26, 377-379. [CrossRef] [PubMed]

7. Cohan, C.L.; Cole, S.W. Life Course Transitions and Natural Disaster: Marriage, Birth, and Divorce Following Hurricane Hugo. J. Fam. Psychol. 2002, 16, 14-25. [CrossRef] [PubMed]

8. Norton, R. Measuring Marital Quality: A Critical Look at the Dependent Variable. J. Marriage Fam. 1983, 45, 141-151. [CrossRef]

9. Zimmermann, T.; de Zwaan, M.; Heinrichs, N. The German Version of the Quality of Marriage Index: Psychometric Properties in a Representative Sample and Population-Based Norms. PLoS ONE 2019, 14, e0212758. [CrossRef] [PubMed]

10. Topp, C.W.; Østergaard, S.D.; Søndergaard, S.; Bech, P. The WHO-5 Well-Being Index: A Systematic Review of the Literature. Psychother. Psychosom. 2015, 84, 167-176. [CrossRef] [PubMed]

11. Hawthorne, G.; Herrman, H.; Murphy, B. Interpreting the WHOQOL-Brèf: Preliminary Population Norms and Effect Sizes. Soc. Indic. Res. 2006, 77, 37-59. [CrossRef]

12. Cohen, S.; Kamarck, T.; Mermelstein, R. A Global Measure of Perceived Stress. J. Health Soc. Behav. 1983. [CrossRef]

13. Kroenke, K.; Spitzer, R.L. The PHQ-9: A New Depression Diagnostic and Severity Measure. Psychiatr. Ann. 2002, 32, 509-515. [CrossRef] 
14. Kroenke, K.; Spitzer, R.L.; Williams, J.B.W.; Monahan, P.O.; Löwe, B. Anxiety Disorders in Primary Care: Prevalence, Impairment, Comorbidity, and Detection. Ann. Intern. Med. 2007, 146, 317-325. [CrossRef] [PubMed]

15. Fagerland, M.W. T-tests, non-parametric tests, and large studies-A paradox of statistical practice? BMC Med Res. Methodol. 2012, 12, 78. [CrossRef] [PubMed]

16. Leonard, K.E.; Rothbard, J.C. Alcohol and the marriage effect. J. Stud. Alcohol. 1999, s13, 129-146. [CrossRef] [PubMed] 